\title{
Spatial organization and economic analysis in sustainable transit oriented development
}

\author{
N. Mohajeri \\ Department of Art and Architecture, Islamic Azad University, \\ South Tehran Branch, Iran
}

\begin{abstract}
Transit oriented development (T.O.D.) is one of the most important subjects in sustainable urban development. This strategy has been taken for decreasing the journey demand especially combining land use and transportation development with focus on the land development around railway stations. According to this statement, the provision of a station complex is considered as an option for approaching a sustainable urban transportation.

This paper analyses the spatial organization underground stations after a brief defining of transit oriented development. This paper also is going to discuss the benefits of a station complex which is made according to sustainable development with focus on the economical effects.
\end{abstract}

Keyword: spatial organization, sustainability, transit oriented development.

\section{Introduction}

In order to get into economic development, the existence of an inner city rail transportation network is considered an indispensable tool for success. Since three decades ago forward looking urban designers and urban planners in connection with intelligent development in cities, in order to minimize demands for daily inner city trips, have put great emphasis on the coordination of land use and transportation systems. This idea nowadays clearly implies concentration of various daily activities in and around underground or city railway stations. This impact of such magnitude particularly in areas immediately next to the stations is quite evident and by passage of time every station creates a magnet of its own consequentially ending in gathering up of an assortment of utilities and intense 
built up around it all relative to the station's position in the city and on the zonal level.

Being next to and near the stations facilitates easier access for residential, commercial, and service centers while simultaneously helping to save on time and expenses. The effects of such advantages in other areas are best reflected in increasing of the value of adjoining properties and that means there is possibility of gaining new revenues which can be spent on construction and maintenance of rail transport systems. Our article is concentrating on an appraisal of underground economic impacts on the development in areas situated around stations' circle of influence.

\section{History and definition}

During the Second World War in the United States low density built up and development plans inclusive of non centralized utilities formed the method of land use in cities. Such a manner of urban development and planning encouraged an amazing growth in the number of personal and commercial journeys during those years. In recent years the impacts of rising volume of journeys and rapid and extensive expansion of cities have created the problem of air and sound pollution as well as the rise in the level of greenhouse gases. Now urban planning organizations and transport agencies are taking up policies and strategies with regard to new approaches to the patterns of built up density and appropriate usage of land.

Calthorpe in 1993 presented an elaborate picture of transport oriented urban development. He has defined transport oriented development or TOD as a space or particular limit consisted of high density residential built up, small shops, administrative and commercial complexes and other utilities. Stores and service centers are situated in its commercial core where on-foot movement up to 600 meters (or 10 minutes walk) to places of residence is feasible. The transport station is right in the center. Utilities inside the core are totally horizontal. Apartments and offices are situated on upper floors above shopping centers.

Other areas with lower density are within 600 and 1600 meters distance from the core .These areas could be used for locating residential suites of various sizes, small parks, schools and some light industries. In the design of houses the emphasis is on a mixture of traditional and modern characteristics in such a way that their easy access to out street parking could be available. Streets in the vicinities are mainly corresponding to the network pattern and facilitate access to the core by foot or bicycle.

\section{Principles observed in implementation of station complexes}

\subsection{Space planning in transit stations}

The principal users of station complexes are pedestrians who travel on foot. All inner city journeys also includes elements of walking whether in the beginning or at the end of a journey. Therefore space planning for a station complex around 
light railway lines has to be in such a way that on foot pedestrians could make an effective use of it, in other words the maximum distance from the station should not exceed a walk of 5 to 10 minutes or a distance of 600 meters.

\subsection{Land use design according to transit oriented}

The design of land use in areas adjacent to light railway transport stations has to have the following characteristics:

- High built up density in working and residential environments

- Moving journey time to other non peak hours

- Encouraging the public to use light city train and roads in their journey routes

- Encouraging the distribution of non working hours during the day and the week

- Creating motivation among on foot pedestrians to use stations

The various utilities located in this limit includes the following items:

- High schools and higher education institutions

- $\quad$ Residential areas with average and high built up density

- Small shops

- Service centers

- Cultural and entertaining centers

\subsection{Land use combination}

The space allocated to a station has to provide favorable conditions for combining residential centers, offices, shopping and service centers. The combination of land use could be of horizontal or vertical arrangement in such a way that several utilities are located in multi storied buildings or can be scattered in various adjacent buildings. The importance of this is derived from the fact that in the influence circle of a station it is possible to cover various needs through on foot movement.

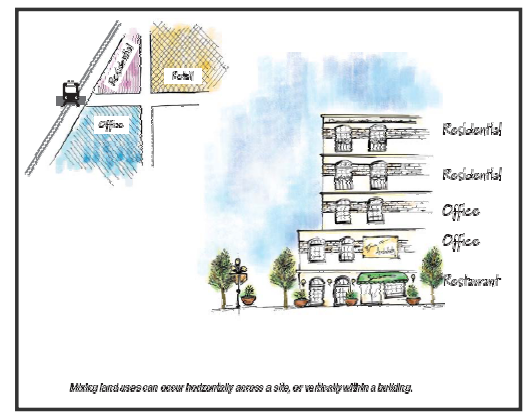

Figure 1: Combined land uses around a station in horizontal, vertical arrangements and within buildings, floors. 


\subsection{Restraining land uses when not harmonious with transportation system}

Since the major emphasis of station complexes is on transfer transportation and pedestrians, it is necessary to prevent the spread of land uses which encourage the use of personal vehicles within station's sphere of influence. Such utilities are as follows:

- Utilities occupying large land with low build up density

- Utilities requiring large space for guaranteeing the prevention of damages to the surrounding environment

- Utilities requiring the use of private vehicle

- Utilities which impose limitation on foot access

Some examples of these utilities are as follows:

Vehicles, centers of service and repair/ centers of sale and purchase of vehicles/carwash centers/fuel stations/public parking/small industries/goods warehouses/low density commercial centers/low density residential areas.

Such areas should not be within immediate reach of station space and the best option is keep them off the circle of station's planning domain as much as possible.

\subsection{Improving built up density around station}

Built up density around transit stations should be increased or in other words such density must be affected in places where the best access to the rapid transportation system is available. Furthermore, high density utilities and buildings should rather be located in the nearest points to the city railway station building.

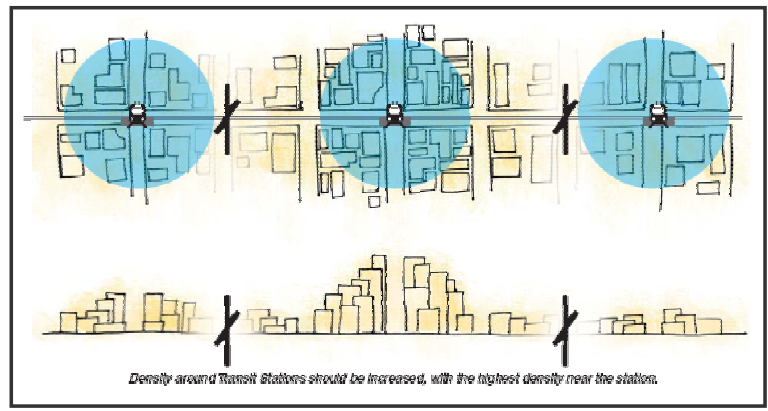

Figure 2: Utilities and buildings of high density near city railway station building.

\subsection{Minimizing the impacts of density}

With the increase in density around stations inclination towards living near centers situated off this limit grows and therefore some solutions to confront such phenomenon have to be found. 


\subsection{Designing good quality routes for pedestrians}

A trouble free and suitable route for making connection by on-foot movement should possess the following characteristics:

Shortness/ continuity/ obstruction free/ safety/ plainness and clear definition/ design based on climatic condition of the city (for example the necessity of sheltering people from sharp sunshine).

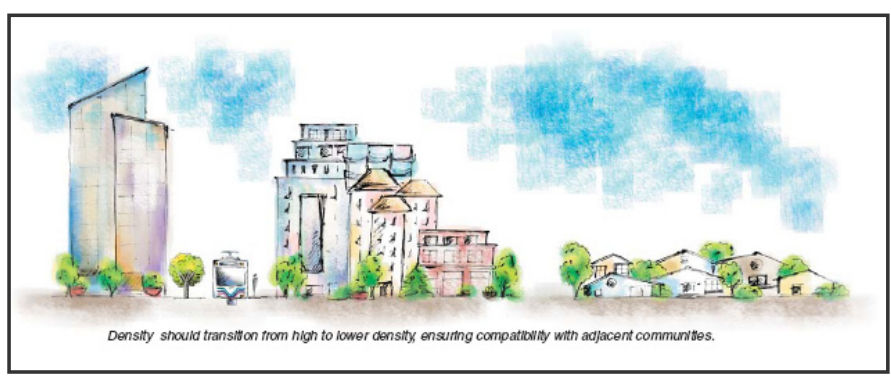

Figure 3: Harmonizing general built up density in surrounding area with station complex.

\subsection{Compact development structure}

The placement of buildings in a compact space should be managed in such a way that any access to them for pedestrians be easy either by main passages or less prominent passages needless of long walk from one building to another.

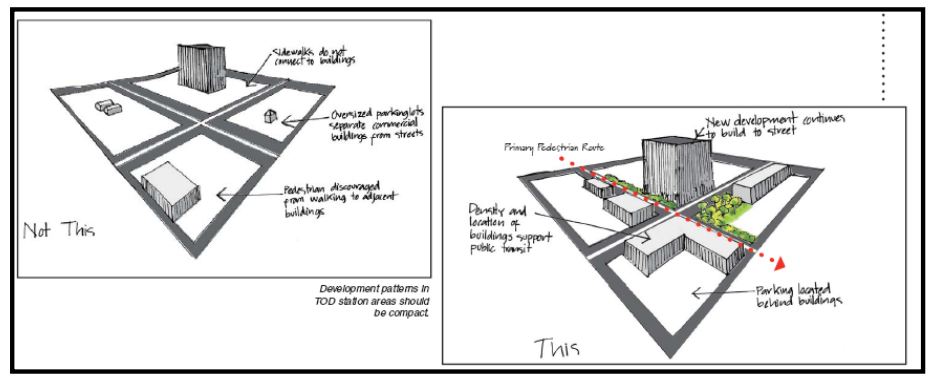

Figure 4: Compact development pattern for developing station's surroundings.

\subsection{Taking into consideration the climatic characteristics of all seasons}

In designing main walking routes and also transport facilities, sheltering devices to protect people from climatic phenomenon's (sun rays, rain, snow etc...) should be taken into consideration. This purpose could be reached by the way of constructing closed spaces in stations and covered porches outside. 


\subsection{Placing parking lot in right spots}

The spaces given to parking lots should not hinder the comfortable and safe movements of pedestrians within station. The major parking must be accessible by main roads and other passages in such a way that they do not come into contact with pedestrians, routes. The pedestrian's passages which may lead to transit station, main administrative spaces, and high density residential areas must be separated from parking spaces. Parallel to pedestrian's passages leading to transit station, parking lots should be designed and constructed in such a manner that passing vehicles traffic could be kept at its minimum in the routes of walking public.

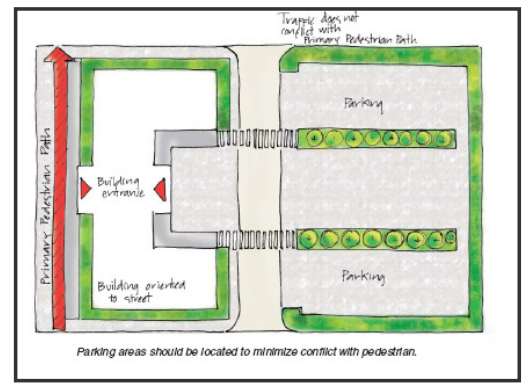

Figure 5: Appropriate placement of parking lots around station with regard to the pedestrian's passageways.

\section{The goals of constructing station complexes}

The project is concerned with planning for areas adjacent to station based on policies and methods of materializing the following key goals:

- Optimum use of lands around station

An optimum use of station surrounding land will support the interests of passengers as well as providing groups of local people with a place for launching various activities. The other positive effect of station complexes is to make ground for redistribution of land exploitation among sections devoted to services, employment and building activities in the city.

- Density growth in the neighborhood of a station

Growth in the level of density around stations with regard to resultant passenger increase would entail rise in efficiency of stations and would support rapid transportation services.

- A pedestrians oriented design

The station complexes would maintain an appropriate, comfortable, straightforward and safe connection among pedestrians in pursuit of supporting pedestrian friendly stations and to create motivation for choosing public transportation as the means of commute. 
- Changing every station and its vicinity into an attractive place for pedestrians

Due to existence of such facilities in the limits of station complexes, every space in a station could become an appealing and unique environment in the eyes of on-foot visitors and consequently offer revenue generating potentials of considerable importance.

- $\quad$ Parking management and the management of vehicle transportation

Designs and architectures in the limits of station complexes are planned in such a way that would not allow transportation systems like bus system, private vehicles and parking to hinder the movement of on-foot pedestrians and damage their heath by creating pollution.

- Planning in local communities

Transportation oriented urban development has to produce some advantages for the benefit of local residents. These advantages could consist land use increase, appropriate services, building activities of various types, increase in the number of transport service options and more compatibility of walking environment.

\section{The benefits of constructing station complexes}

\subsection{The benefits of constructing station complexes based on principles of continuous development}

The benefits of station complexes based on principles of sustainable development are shown in the following model:

Table 1: The benefits of station complexes based on principles of sustainable development.

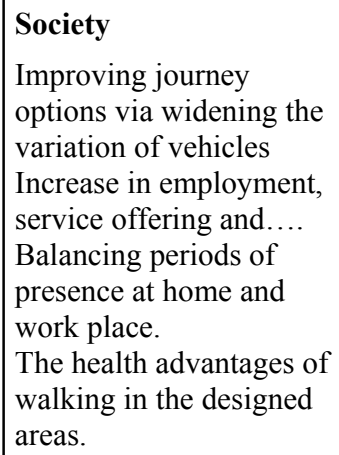

\section{Economy}

Maximum exploitation of rapid transportation infrastructure.

Decrease in the level of traffic and the consequent expenses.

New formation of obsolete or misused industrial and commercial environment.

\section{Environment}

Decrease in the level of greenhouse gases Decrease in consumption of energy by optimum exploitation of land and transportation Upgrading the quality of air. 


\subsection{Environmental impacts}

If we study the question of traveling by private vehicles from the point of view of energy consumption we realize that the volume of VMT distinctive in a direct way affects the environment of concerned area. The residents of area recognize and understand fully the fuel consumption related symptoms such as air pollutions; air pollution oriented illnesses as well as negative effect of air pollution on the quality of water in the area.

Studies show that TOD negative effects in all times are close to $46 \%$ less than those related to traditional systems of transportation. These effects such as fuel consumption, carbon dioxide and carbon black articles environmentally affect the health of citizens and damage the beauty of the city.

Dissemination of carbon dioxide as a result of fuel burning create urban pollutions beyond urban areas leaving negative impression on pastures and the climatic conditions. The negative effects left by carbon dioxide on pastures equals in value the stretch of woodland which has to be destroyed in order to produce fuel. Illustrating negative effects of carbon dioxide in this manner would show more clearly negative effects generated by its dissemination through burning of fossilized fuels.

\subsection{Economic impacts}

Station complexes produce many economic impacts in societies and cities at large. They create extensive variations in residential units which correspond to the needs of different generations and their incomes. It also could act as catalyst for ever more development of city and the economy. Executors of TOD projects benefit from reduction of occupied lands which would otherwise be used as car parking lot. On the other hand the residents of the area also benefit from reduction of transport costs and consequent rise in their power of spending.

\subsubsection{Short term impacts}

- Saving: Such benefit mainly comes from providing services to greater number of people in a smaller area.

- Savings generated by suitable location: Such benefits are gained by creating opportunity for greater number of people to have access to essential facilities.

In addition to financial gains for local government, also by expansion of such a well planned transportation system the following benefits are accessible:

- Rise in prices of residential lands due to new urban management

- Rise in prices of residential lands due to accessibility of comfort, advanced public transit system and cheaper services.

\subsubsection{Long term impacts}

- Growth in the value of regional assets due to management's appropriate policies which create ground for rise in the revenues derived from tax and land value increase

- $\quad$ Rise in average workforce efficiency 
- $\quad$ Rise in general efficiency facilitated by creation of high density cities and use of efficient systems of transportation.

- Creating a greater share of regional revenues relative to those of other regions by optimum resource management

- No guarantee could be given for full realization of all above mentioned economic benefits but there is no doubt even the realization of even a small portion of these benefits could have considerable impacts on any region.

\subsection{Appraisal of benefits and impacts of utilizing station complexes}

An appraisal of benefits and impacts of TOD could be studied in the form of two main groups. The following table shows the positive impacts of TOD for governments and societies:

Table 2: $\quad$ The positive impacts of TOD for governments' societies.

\begin{tabular}{|l|l|}
\hline \multicolumn{1}{|c|}{ Societies } & \multicolumn{1}{c|}{ Government } \\
\hline $\begin{array}{l}\text { Increase in accessibility of various } \\
\text { areas by creating byways }\end{array}$ & $\begin{array}{l}\text { Rise in the number of public } \\
\text { transportation users }\end{array}$ \\
\hline $\begin{array}{l}\text { Improvement in condition of local } \\
\text { traffic }\end{array}$ & $\begin{array}{l}\text { Rise in revenues of transport } \\
\text { orientation }\end{array}$ \\
\hline $\begin{array}{l}\text { Rise in high density infrastructures } \\
\text { and variation in usage of lands which } \\
\text { help to make optimum use of lands }\end{array}$ & $\begin{array}{l}\text { Rise in revenues gained from tax and } \\
\text { profit of urban land development }\end{array}$ \\
\hline $\begin{array}{l}\text { Development in economy by } \\
\text { methods such as increasing the level } \\
\text { of employment }\end{array}$ & $\begin{array}{l}\text { Reinforcement of organizational } \\
\text { relations }\end{array}$ \\
\hline
\end{tabular}

\section{Conclusion}

As explained in the paper the limits of surrounding area around inner city stations right from the first phase of implementation could be defined as the area of change which in various times relative to created capacities would take in a new degree of density and land usage. It is necessary by taking into account the goal of logical utilization of created opportunity such changes be settled and managed realistically. The recognition of opportunities and capacities for organization and planning what inevitably would take place in future is necessary and unavoidable.

Investment in city railway projects would create ground for various changes such as economic developments within stations, circle of influence. These developments in a chain of time would bring about rise in the values and also would help many changes to appear on the face of urban life. In addition to that, investment in the city railway projects would set off space rearrangement of areas adjacent to the stations. 


\section{References}

[1] J.M. Pertchik \& A.R. West., TOD initiative west Palma Marlette and feasibility study Report, Treasure coast Regional Planning Council, October 2004.

[2] S. Polikov., Leander TOD market Analysis, Capital Market Research, INC, Jan. 2005.

[3] Costs of Sprawl Transit Cooperative Research Program, 2002.

[4] Norman Y. Mineta A New Planning Template For TOD, 2004

[5] Robert Cervero Accessible Cities and Regions A Framework for Sustainable Transport and Urbanism in the 21st Century

[6] Peter Newman Transit Oriented Development an Australian Overview, 2005

[7] Kathi Holt-Damant Transit Oriented Development, Making Happen, 2002.

[8] Peter J. Marcotullio The compact city environmental transition theory and Asia-Pacific urban sustainable development, 2004

[9] Walter Siembab Technology as Part of Transit Oriented Developments, 2004

[10] Richard Willson Parking Policy for TOD California State Polytechnic University Pomona, 2002.

[11] Michael Gilat Coordinated Transportation and Land Use Planning in the Developing World - The Case of Mexico City, 2004.

[12] Ivonne Audirac Marketing Transit Oriented Design The Florida Department of Transportation Public Transit Office 2004.

[13] Shaoming Zhang Feasibility Study on Transit-Oriented Development Using Urban-Form and Non-Urban-Form Variables, 2005 